Journal of Advanced Research in Fluid Mechanics and Thermal Sciences

Journal homepage: www.akademiabaru.com/arfmts.html ISSN: 2289-7879

\title{
Effect of Thermally Formed Alumina on Density of AIMgSi Alloys Extrudate Recycled Via Solid State Technique
}

\author{
Abdullah Wagiman ${ }^{1,}{ }^{*}$, Mohammad Sukri Mustapa ${ }^{2}$, Mohd Amri Lajis ${ }^{1}$, Shazarel Shamsudin ${ }^{1}$, \\ Mahmod Abd Hakim³, Rosli Asmawi ${ }^{2}$ \\ 1 Sustainable Manufacturing and Recycling Technology, Advanced Material Manufacturing Center (SMART-AMMC), Universiti Tun Hussein Onn \\ Malaysia, Johor, Malaysia \\ 2 Structural Integrity and Monitoring Research Group, Faculty of Mechanical and Manufacturing Engineering, Universiti Tun Hussein Onn \\ Malaysia, Johor, Malaysia \\ 3 Sustainable Product Development Research Group, Center for Diploma Studies, Universiti Tun Hussein Onn Malaysia, Johor, Malaysia
}

\section{ARTICLE INFO ABSTRACT}

\section{Article history:}

Received 17 May 2021

Received in revised form 15 August 2021

Accepted 18 August 2021

Available online 22 September 2021

\section{Keywords:}

In-situ alumina; thermal treatment; aluminium recycling; solid state; hot extrusion

\begin{abstract}
Solid state recycling of aluminium via hot extrusion is a sustainable technique. The process performed before hot extrusion plays a vital role on the extrudate properties. In this study, the effect of naturally and thermally formed in-situ alumina on the extrudate density were investigated. Fours type of material identified as a solid asreceived, non-treated recycle chip, $300{ }^{\circ} \mathrm{C}$ thermally treated recycle chip and $500{ }^{\circ} \mathrm{C}$ thermally treated recycle chip were prepared for the experiment. Prior to extrusion, the recycle chips were compacted into a chip-based billet, preheated and immediately extruded into a semi-finished product. The density test performed on the chip-based extrudate found that the type of chips influenced the density. The chip-based extrudate made of $300{ }^{\circ} \mathrm{C}$ and $500{ }^{\circ} \mathrm{C}$ thermally treated chips resulted in higher density than solid as-received and non-treated chips. Chip-based extrudate produced from 500 ${ }^{\circ} \mathrm{C}$ thermally treated chips resulted in density of $2724 \mathrm{~kg} / \mathrm{m}^{3}$, which is the highest among the specimen. This density value was $0.7 \%$ higher compared to the solid asreceived extrudate. Microstructure examination on the cross-section revealed the alumina entrapped in the chip-based extrudate. The alumina entrapped in $500{ }^{\circ} \mathrm{C}$ thermally treated chips specimen was more prone than the non-treated and $300{ }^{\circ} \mathrm{C}$ thermally-treated chips. This finding explains the variation in the extrudate density.
\end{abstract}

\section{Introduction}

In recent years, there has been an increasing trend in research works that are focused on the issue related to sustainable manufacturing. The study includes recycling of aluminium chips using a solid-state technique, in which the process is performed in a melt less process [1-5]. The process used $95 \%$ less energy than the conventional technique [6], which conserve natural resources and a safe environment due to less greenhouse gas emission. Without melting and casting, the process required less processing stage as shown in Figure 1. The process transforms the recycled chips into a

\footnotetext{
* Corresponding author.

E-mail address: abdulla@uthm.edu.my

https://doi.org/10.37934/arfmts.87.2.137144
} 
semi-finished product directly through a severe deformation process. In comparison to the conventional technique, the process can transform the aluminium chips in a short cycle time, less workforce, and cost-saving.

Recycling aluminium via solid-state technique can be performed using various types of severe deformation processes. To this date, the deformation process such as forging [7-9], rolling [10,11] and extrusion [12-14] have been applied in previous research works. It has been claimed in a majority of research studies that the method is feasible in transforming recycled chips into semi-finished products. Moreover, the mechanical properties of the product made from recycling chips are also comparable to the as-cast billet extrudate.

The extrusion process transformed the recycling chips into a fixed cross-sectional profile extrudate. In this process, sufficient temperature and pressure are necessary for providing the required stress to deform the chips severely. The deformation causes the chip to shear, disrupts, and breaks the in-situ alumina layer that naturally forms on the chip surface into the ultrafine particle [15]. The fragmentation of the alumina layer removes the chip consolidation barriers, allowing contact between the fresh aluminium and consolidating the chip into the bulk. The entrapped ultrafine alumina reinforced the aluminium matrix, causing lattice distortion which impedes the dislocation motion and increases the strength of the material. With increasing the amount of alumina reinforcement in the matrix, the strength of the extrudate increased.

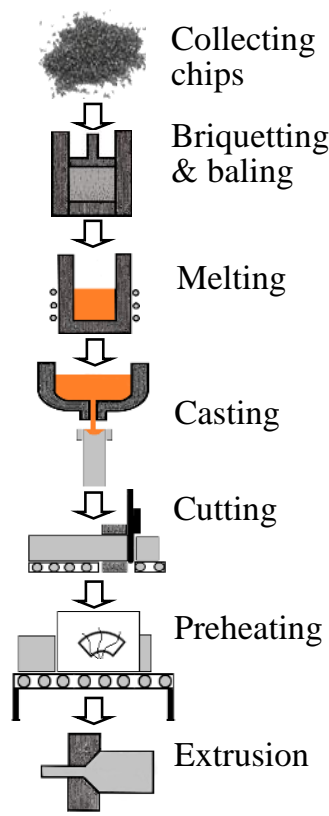

(a)

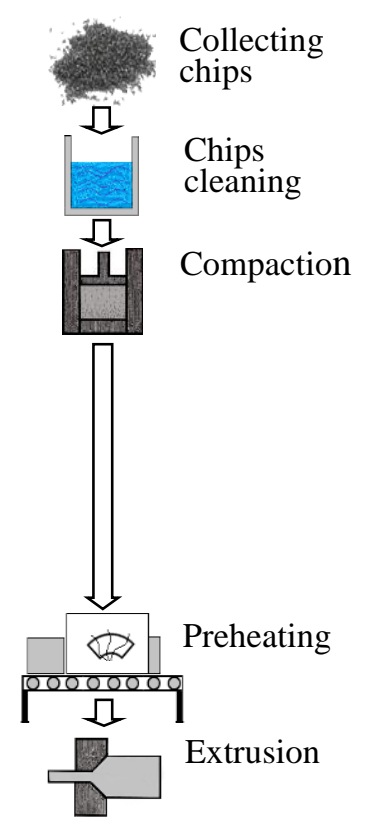

(b)

Fig. 1. Aluminium recycling technique (a) conventional (b) direct recycling [8]

Mixing the chips with other reinforcement material could enhance the aluminium alloys properties [16]. Lajis et al., [4] reported that mixing the chip with alumina powder significantly affected the extrudate's strength. They found that adding alumina powder as much as $2 \%$ into the chips has improved the extrudate's strength. However, too much alumina powder reduces the strength and ductility of the extrudate. Apart from weight fraction, the size of alumina powder and aluminium chips also affected the extrudate properties [17].

The usage of alumina powder as reinforcement material in direct recycling of aluminium chips has the drawback. The alumina powder tends to agglomerate, which weakened the chips 
consolidation and thus worsened the extrudate properties. Furthermore, the powders and the chips have no bond, limiting the amount of powders sticks on the chip surface. Most of the powders will precipitate on the bottom side as it is small compared to the chip. It means that increasing the powder's weight fraction will not represent the real weight fraction entrapped in the extrudate. This problem is also affecting the uniformity of the distribution of the powder. The alumina and the chip may need to be bonded together before extruded in getting this problem solved.

Alternatively, the formation of alumina layer on the chip surface itself can be used as reinforced material. The reaction of aluminium with atmospheric oxygen will naturally generate thin film of alumina on the surface about 4 nanometers $[18,19]$. The alumina layer could be thermally enriched in-situ by employing thermal treatment. Depending on thermal treatment temperature, the treatment could result in alumina layer with a thickness of up to 50 nanometers. Besides, the treatment could also soften the chips, allowing the cold compaction to be performed at a much lower pressure than the compaction of non-treated chips

Since the hot extrusion on compacted billet can disperse the alumina layer into the fine particle, the effect of thermally form alumina on the chip is expected to have the same impact as the addition of alumina powder. However, until today, research investigating this technique is rarely reported. Therefore, in this work, the effect of the thermal-treated chips on the extrudate density was investigated. The variation in density will indicate the impact of the thermal treatment on the extrudate's physical properties.

\section{Methodology}

In this work, the machining chips were produced by face milling of AA6061-T650 aluminium alloys block using MAZAK CNC machine. Table 1 shows the composition of the aluminium alloys. The cutting was operated with side cut end mill using a cutting tool of $10 \mathrm{~mm}$ in diameter, $345 \mathrm{~mm}$ per second cutting speed, $1 \mathrm{~mm}$ feed per tooth, and $1 \mathrm{~mm}$ depth of cut. The oil-based coolant was employed to control the machining temperature. The chips undergo acetone cleaning in an ultrasonic bath to remove the coolant and other contaminants. The chips were then dried in an oven at $100{ }^{\circ} \mathrm{C}$ for 1 hour to burnt out the acetone, water, and providing a clean chip surface.

\section{Table 1}

AA6061-T650 chemical composition

\begin{tabular}{llllllllll}
\hline Element $\mathrm{Si}$ & $\mathrm{Fe}$ & $\mathrm{Cu}$ & $\mathrm{Mn}$ & $\mathrm{Mg}$ & $\mathrm{Cr}$ & $\mathrm{Zn}$ & $\mathrm{Ti}$ & $\mathrm{Al}$ \\
\hline Wt (\%) & 0.67 & 0.52 & 0.28 & 0.02 & 1.10 & 0.19 & 0.01 & 0.02 & Rest \\
\hline
\end{tabular}

Four types of extrudate materials were prepared and labelled accordingly as shown in Table 2. The materials are solid as received, non-treated chip (NT), chips thermal treated at $300{ }^{\circ} \mathrm{C}$ (TT300) and chip treated at $500{ }^{\circ} \mathrm{C}$ (TT500). A solid as-received of AA6061-T650 was extruded for comparison with extrudate made from recycled chips. The TT300 and TT500 were thermally treated in the induction furnace for 1 hour. The chips were immediately cooled down naturally to ambient temperature after reaching the treatment time. The chips were then filled into the cylindrical cavity mould $30 \mathrm{~mm}$ in diameter and $100 \mathrm{~mm}$ in length. A press machine was used to compact the chips into a compacted chip billet for ease of handling. During the compaction process, the weight of the chips and compression force was controlled to produced a simmilar density for all billets of the compacted chip. 


\section{Table 2}

Extrudate labels

Extrudate material As-received Non-treated chip Thermal-treated chip at $300{ }^{\circ} \mathrm{C}$ Thermal-treated chip at $500{ }^{\circ} \mathrm{C}$

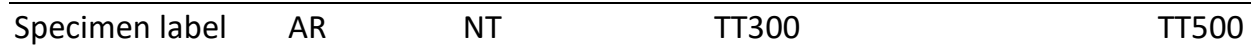

Prior to hot extrusion, the compacted-chip billets were preheated to $550{ }^{\circ} \mathrm{C}$ for 1 hour in the induction furnace. The billet is then immediately taken out from the furnace and extruded using a 300 tones horizontal press machine at a speed of $3 \mathrm{~mm} / \mathrm{s}$. The billet was driven by the plunger to pass through the flat face cylindrical orifice die with the extrusion ratio of 12 and die temperature of $350{ }^{\circ} \mathrm{C}$. Figure 2 show the extrusion machine and the die used in this work.

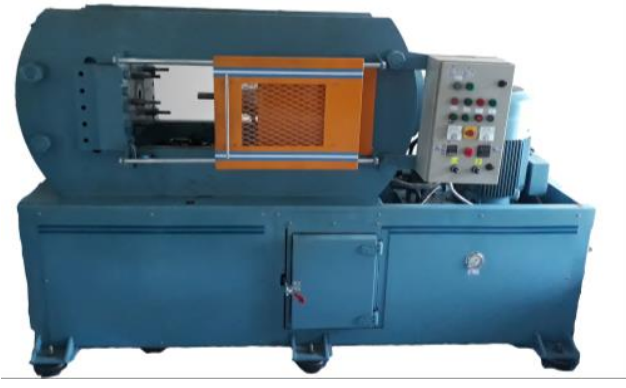

(a)

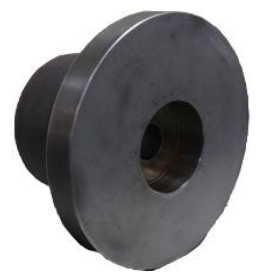

(b)

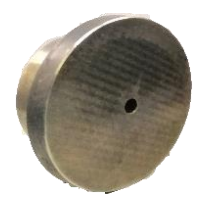

(c)

Fig. 2. Extrusion equipment (a) Extrusion machine (b) Die container (c) Flat face die

The extrudate billet was cut off just after the extrusion was completed and naturally cool instantly to ambient temperature. A solid as-received of AA6061-T650 was also extruded for comparison. Figure 3 shows the chips, the billet of compacted chips and the extrudate of the recycled chip. Without additional heat treatment, the extrudate was cut into a sample parallel to the extrusion direction. The sample was ground by alumina sandpaper and polished by cloth associated with a various diamond polishers. The sample was etched by Baker reagent and examined using an optical microscope (OPM). The density of the extrudate samples was measured based on Archimedes's principles.

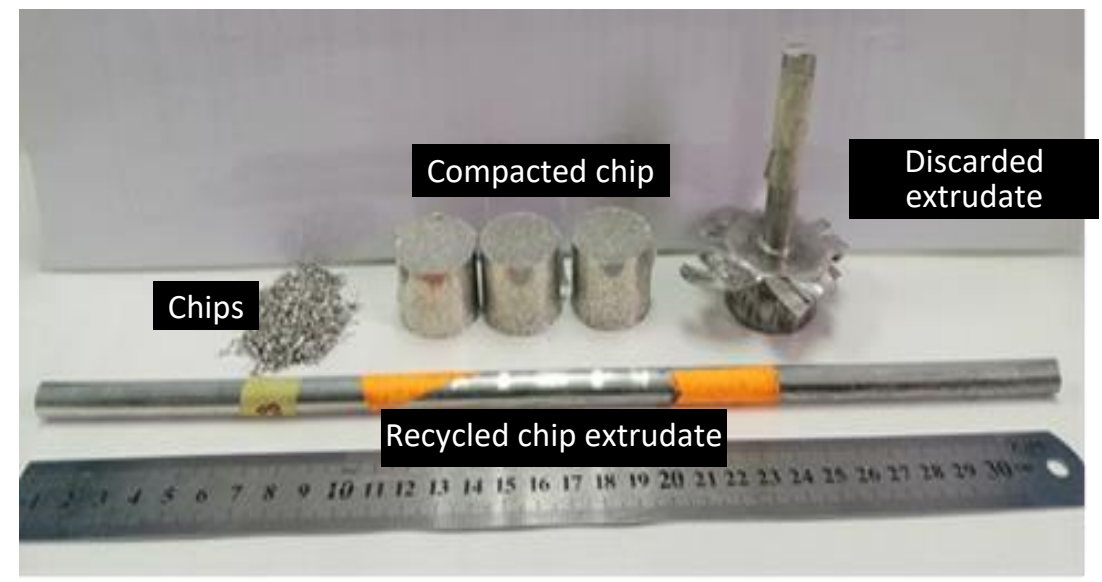

Fig. 3. Recycle chips and the products 


\section{Result}

The density of the extrudates made from the different chip is depicted in Figure 4. The results showed that material resulted in different density value. For all extrudates, the density values were in the range of $2704 \mathrm{~kg} / \mathrm{m}^{3}-2724 \mathrm{~kg} / \mathrm{m}^{3}$. The extrudate of AR has a density of $2704 \mathrm{~kg} / \mathrm{m}^{3}$. All extrudate made from recycling chips has a density higher than the AR. The extrudate of TT500 has a density of $2724 \mathrm{~kg} / \mathrm{m}^{3}$, the highest among the sample. The density was about $0.7 \%$ higher compared to the AR sample.

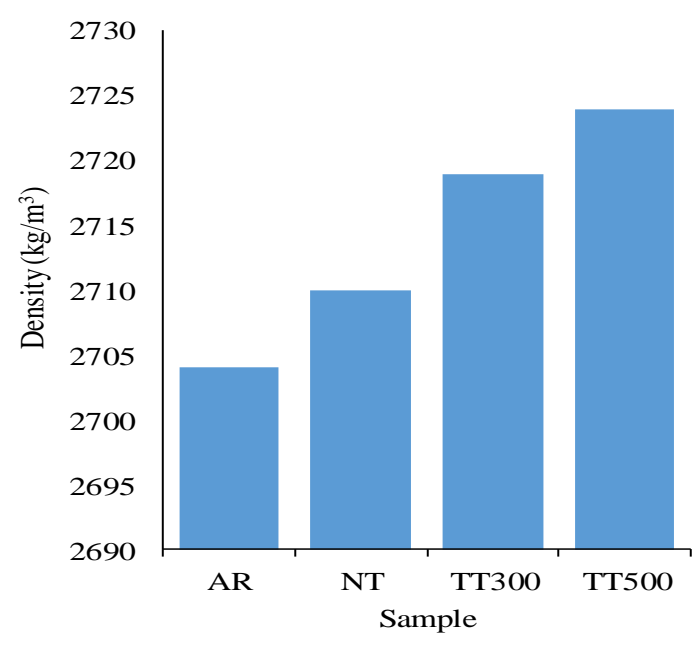

Fig. 4. Density of extrudate

Meanwhile, the extrudate density of the thermal-treated chip was higher than the extrudate made of non-treated chips. The NT sample has a density of $2710 \mathrm{~kg} / \mathrm{m}^{3}$. The density rose $5 \mathrm{~kg} / \mathrm{m}^{3}$ to $2715 \mathrm{~kg} / \mathrm{m}^{3}$ when the chips were thermal-treated at $300{ }^{\circ} \mathrm{C}$. Increasing the treatment temperature to $500{ }^{\circ} \mathrm{C}$ caused the density gain further to $2724 \mathrm{~kg} / \mathrm{m} 3$. The density increment indicated that the density of the extrudate relied on the chip treatment temperature.

Microstructure examination on the extrudate cross-section of AR, NT and TT500 was depicted in Figure 5. For all samples, it can be observed that the fine precipitates of $\mathrm{Mg}_{2} \mathrm{Si}$ and FeAISi were the primary substance observed in the microstructure. The $\mathrm{Mg}_{2} \mathrm{Si}$ and FeAISi could be identified from the black and white colors, respectively. This finding was similar to the study by Voort et al., [20]. The AR sample consists of coarse $\mathrm{Mg}^{2} \mathrm{Si}$ and FeAISi while the NT and TT500 consist of mixed coarse and fine $\mathrm{Mg}^{2} \mathrm{Si}$ and FeAlSi.

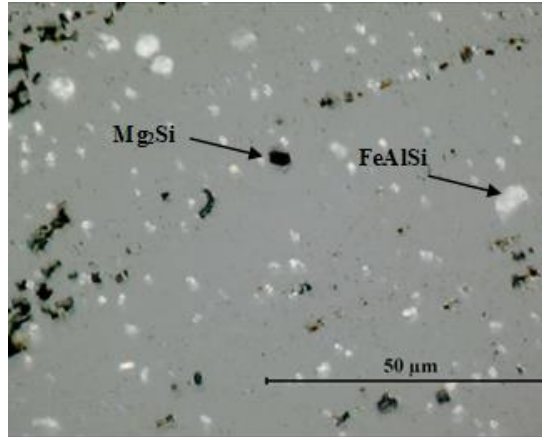

(a)

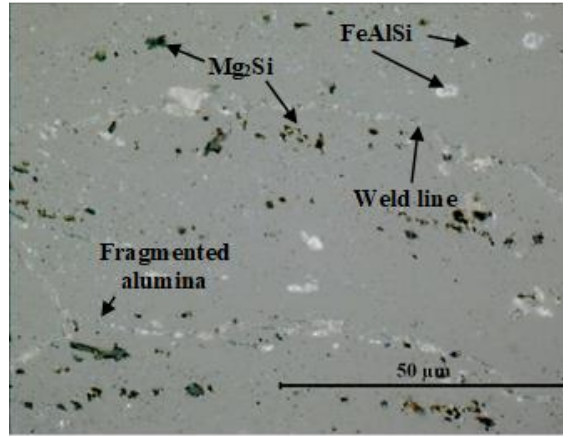

(b)

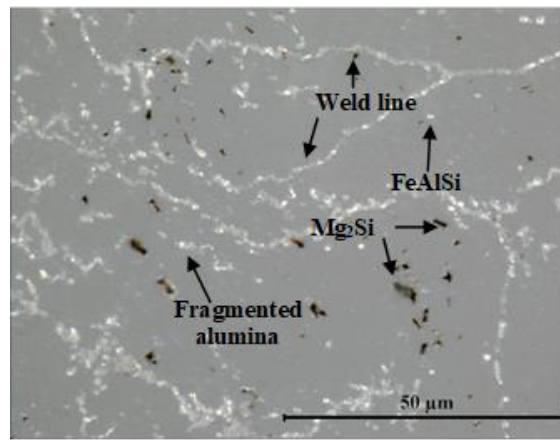

(c)

Fig. 5. Extrudate microstructure (a) AR (b) NT (c) TT500 
The AR microstructure revealed no chip weld line since it was extruded from solid as-received. The NT and TT500 clearly showed chip weld lines in the microstructure. The chip weld line was formed due to chip consolidation. Besides, the chips consolidation in NT and TT500 were sound good, in which no micropore and crack existed in the microstructure.

Meanwhile, the fragmented alumina layer was also observed entrapped in the aluminium matrix of all chip-based extrudate. The NT observed that the alumina was mainly entrapped on the chip weld line. In contrast with NT, the presence of alumina in the microstructure of the TT500 was more prone than the NT. The TT500 showed the alumina scattered in the entire microstructure, although some were also observed in the weld line.

\section{Discussion}

The density variation of AR, NT, TT300, and TT500 extrudate could be explained by the presence of alumina in the aluminium matrix. Since the density of alumina is two times higher compared to aluminium alloys, any increment of the in-situ alumina on the surface of the chip due to thermal treatment would gain the density of the chip-based extrudate. During the hot extrusion, the plunger forced the billet of compacted chips to go through the die cylindrical orifice. The difference in diameter of the billet and the orifice provide high shear stress and severely deformed the compacted billet. The alumina layer that forms either naturally or thermally on the chip surface was severely fragmented into fine particles and entrapped in the aluminium matrix. The higher the amount of insitu alumina formed on the surface would result in higher alumina entrapped in the chip-based extrudate.

The NT sample in which the alumina was naturally formed has a density lower than the thermally formed alumina (TT300 and TT500). The results indicated that the chip treatment temperature played an important role when recycling thermally treated chips. The thermal treatment performed on the chips has enriched the in-situ alumina layer on the aluminium surface [21]. The enrichment of the alumina is depended on the chip treatment temperature. High treatment temperature produced thicker alumina layer. The density relies on the thickness of the in-situ alumina layer that forms on the surface. The thicker the alumina layer resulted in more alumina entrapped in the aluminium matrix. Therefore, the chips treated at high temperature resulted in higher extrudate density than the low-temperature treatment.

Entrapped alumina in the aluminium matrix could answer why the density of the extrudate made from recycling chip is higher than the original alloys. Theoretically, alumina has a density of 3950 $\mathrm{kg} / \mathrm{m}^{3}$, which is about one time higher than the aluminium. Therefore any small increment of the alumina in the matrix could significantly affect the extrudate density. Furthermore, the chips have also been cleaned by ultrasonic cleaning, which removed all contamination on the chips surface. Therefore, it is believed that the increment on the density of the TT300 and TT500 is solely due to alumina enrichment by the thermal treatment. The higher the amount of alumina enriched by the treatment resulted in higher extrudate density.

Instead of density, other researchers also claim that the presence of the alumina layer on the chip surface also affected the other properties. According to [10] and [22], the extrudate of recycling chip shows higher strength properties than the as-received. Therefore, entrapped alumina in the matrix is not a drawback, but it could be manipulated to improve the extrudate's mechanical properties. 


\section{Conclusions}

Direct hot extrusion is a sustainable technique in recycling aluminium chips. The density of the extrudate produced by the technique relies on the process before hot extrusion. In this experiment, the entrapped alumina was found to be the main reason affecting the variation of the density. Nontreated chips that have naturally form alumina was found to have extrudate density less than the thermally treated alumina layer. The alumina was naturally formed on the chip surface due to the reaction between the oxygen and aluminium. The thermal treatment performed on the chips has enriched the alumina. The higher the thermal treatment temperature, the thicker the alumina layer form on the surface, resulting in higher extrudate density. Although the thermal treatment resulted in alumina enrichment on the chips surface and increased the density of the extrudate, but it colud be used to manipulate the strength of the alloys.

\section{Acknowledgement}

This research was funded by a grant from Ministry of Higher Education of Malaysia (TIER 1 H978). Additional supports in terms of facilities were also provided by the Sustainable Manufacturing and Recycling Technology, Advanced Manufacturing and Materials Center (SMART-AMMC), Universiti Tun Hussein Onn Malaysia (UTHM).

\section{References}

[1] Gronostajski, J. Z., J. W. Kaczmar, H. Marciniak, and A. Matuszak. "Direct recycling of aluminium chips into extruded products." Journal of Materials Processing Technology 64, no. 1-3 (1997): 149-156. https://doi.org/10.1016/S0924$\underline{0136(96) 02563-0}$

[2] Gronostajski, J. Z., J. W. Kaczmar, H. Marciniak, and A. Matuszak. "Production of composites from Al and AlMg2 alloy chips." Journal of Materials Processing Technology 77, no. 1-3 (1998): 37-41. https://doi.org/10.1016/S09240136(97)00390-7

[3] Chmura, W., and Z. Gronostajski. "Bearing materials obtained by diffusion bonding of aluminium and aluminium bronze chips." Archives of Civil and Mechanical Engineering 7, no. 2 (2007): 53-66. https://doi.org/10.1016/S16449665(12)60211-8

[4] Lajis, M. A., A. Ahmad, N. K. Yusuf, A. H. Azami, and A. Wagiman. "Mechanical properties of recycled aluminium chip reinforced with alumina (Al2O3) particle: Mechanische Eigenschaften von mit Aluminiumoxid (Al2O3) verstärkten recycelten Aluminiumspänen." Materialwissenschaft und Werkstofftechnik 48, no. 3-4 (2017): 306310. https://doi.org/10.1002/mawe.201600778

[5] Tokarski, Tomasz. "Mechanical properties of solid-state recycled 4xxx aluminum alloy chips." Journal of Materials Engineering and Performance 25, no. 8 (2016): 3252-3259. https://doi.org/10.1007/s11665-016-2194-1

[6] Wagiman, Abdullah, Mohammad Sukri Mustapa, Rosli Asmawi, Shazarel Shamsudin, Mohd Amri Lajis, and Yoshiharu Mutoh. "A review on direct hot extrusion technique in recycling of aluminium chips." The International Journal of Advanced Manufacturing Technology 106, no. 1 (2020): 641-653. https://doi.org/10.1007/s00170-01904629-7

[7] Khamis, S. S., M. A. Lajis, and R. A. O. Albert. "A sustainable direct recycling of aluminum chip (AA6061) in hot press forging employing response surface methodology." Procedia CIRP $26 \quad$ (2015): $477-481$. https://doi.org/10.1016/i.procir.2014.07.023

[8] Kadir, M. I. A., M. S. Mustapa, A. S. Mahdi, S. Kuddus, and M. A. Samsi. "Evaluation of hardness strength and microstructures of recycled Al chip and powder AA6061 fabricated by cold compaction method." In IOP Conference Series: Materials Science and Engineering, vol. 165, no. 1, p. 012012. IOP Publishing, 2017. https://doi.org/10.1088/1757-899X/165/1/012012

[9] Ahmad, A., M. A. Lajis, N. K. Yusuf, and A. Wagiman. "Hot Press Forging as The Direct Recycling Technique of Aluminium-A Review." ARPN J. Eng. Appl. Sci 11, no. 4 (2016): 2258-2265.

[10] Chiba, Ryoichi, Tamon Nakamura, and Mitsutoshi Kuroda. "Solid-state recycling of aluminium alloy swarf through cold profile extrusion and cold rolling." Journal of Materials Processing Technology 211, no. 11 (2011): 1878-1887. https://doi.org/10.1016/i.jmatprotec.2011.06.010

[11] Suzuki, Kazutaka, Xin Sheng Huang, Akira Watazu, Ichinori Shigematsu, and Naobumi Saito. "Recycling of 6061 aluminum alloy cutting chips using hot extrusion and hot rolling." In Materials science forum, vol. 544, pp. 443-446. 
Trans Tech Publications Ltd, 2007. https://doi.org/10.4028/www.scientific.net/MSF.544-545.443

[12] Kuddus, S., M. S. Mustapa, M. R. Ibrahim, S. Shamsudin, M. A. Lajis, and A. Wagiman. "Physical Characteristics of Solid State Recycled Aluminum Chip AA6061 Reinforced with Silicon Carbide (SiC) by using Hot Extrusion Technique." In Journal of Physics: Conference Series, vol. 1150, no. 1, p. 012004. IOP Publishing, 2019. https://doi.org/10.1088/1742-6596/1150/1/012004

[13] Rady, Mohammed H., Mohd Sukri Mustapa, S. Shamsudin, M. A. Lajis, and A. Wagiman. "Microhardness and Microstructure of Hot Extrusion Parameters in Direct Recycling of Aluminium Chip (AA 6061) by ANOVA Method." In Journal of Physics: Conference Series, vol. 1150, no. 1, p. 012069. IOP Publishing, 2019. https://doi.org/10.1088/1742-6596/1150/1/012069

[14] Shamsudin, S., M. A. Lajis, Z. W. Zhong, A. Ahmad, and A. Wagiman. "Weld strength in solid-state recycling of aluminum chips: Schweißnahtfestigkeit im Festkörper-Recycling von Aluminium-Spänen." Materia/wissenschaft und Werkstofftechnik 48, no. 3-4 (2017): 290-298. https://doi.org/10.1002/mawe.201600776

[15] Fogagnolo, J. B., E. M. Ruiz-Navas, M. A. Simón, and M. A. Martinez. "Recycling of aluminium alloy and aluminium matrix composite chips by pressing and hot extrusion." Journal of Materials Processing Technology 143 (2003): 792795. https://doi.org/10.1016/S0924-0136(03)00380-7

[16] Joharudin, Nurul Farahin Mohd, Noradila Abdul Latif, Mohammad Sukri Mustapa, Nur Azam Badarulzaman, and Muhammad Faisal Mahmod. "Effect of Burning Temperature on Rice Husk Silica as Reinforcement of Recycled Aluminium Chip AA7075." Journal of Advanced Research in Fluid Mechanics and Thermal Sciences 68, no. 1 (2020): 125-132. https://doi.org/10.37934/arfmts.68.1.125132

[17] Samuel, M. "Reinforcement of recycled aluminum-alloy scrap with Saffil ceramic fibers." Journal of Materials Processing Technology 142, no. 2 (2003): 295-306. https://doi.org/10.1016/S0924-0136(03)00585-5

[18] Juergens, L. P. H., W. G. Sloof, F. D. Tichelaar, and E. J. Mittemeijer. "Structure and morphology of aluminum-oxide films formed by thermal oxidation of aluminum." Thin solid films 418 (2002): 89-101. https://doi.org/10.1016/50040-6090(02)00787-3

[19] Yahaya, Shamy Nazrein Md, I. I. Azmi, Chuan Huat Ng, Chee Fung Lai, Mohd Yussni Hashim, A. Adam, R. Baehr, and Karl Heinrich Grote. "An overview on forming process and heat treatments for heat treatable aluminium alloy." Journal of Advanced Research in Fluid Mechanics and Thermal Sciences 70, no. 1 (2020): 112-124. https://doi.org/10.37934/arfmts.70.1.112124

[20] Vander Voort, George, Beatriz Suárez-Peña, and Juan Asensio-Lozano. "Microstructure investigations of streak formation in 6063 aluminum extrusions by optical metallographic techniques." Microscopy and Microanalysis 19, no. 2 (2013): 276-284. https://doi.org/10.1017/S143192761300010X

[21] Hunter, M. S., and P. Fowle. "Natural and thermally formed oxide films on aluminum." Journal of the Electrochemical Society 103, no. 9 (1956): 482. https://doi.org/10.1149/1.2430389

[22] Wagiman, Abdullah, Mohammad Sukri Mustapa, MOHD AMRI Lajis, S. H. A. Z. A. R. E. L. Shamsudin, Mohd Idrus Mohd Masirin, and Mohammed H. Rady. "Direct Recycling of Aluminium Chips into Composite Reinforced with In Situ Alumina Enrichment." In Materials Science Forum, vol. 975, pp. 165-170. Trans Tech Publications Ltd, 2020. https://doi.org/10.4028/www.scientific.net/MSF.975.165 